\title{
The Impacts of the Service Quality of Coffee Shop Adapting the CoffeeSERV on Customer's Perceived Value, Customer Satisfaction, Behavioral Intention: Focusing on Regulatory Focus Theory
}

\section{CoffeeSERV측정모형을 활용한 커피전문점 서비스품질의 가치지각, 고객만족, 행동의도의 영향관계 연구: 조절초점동기의 조절효과를 중심으로}

\author{
Hwa-Seok KANG(강화석)*
}

Received: August 19, 2019. Revised: September 04, 2019. Accepted: September 10, 2019.

\section{Abstract}

Purpose - This study examined the relationship between service quality, perceived value, customer satisfaction and behavioral intention of coffee shop using CoffeeSERV scale. In this model, CoffeeSERV scale consists of fundamental characteristics, physical environment, confidence, beverage characteristics, and representation factors. In particular, this study tried to demonstrate the moderating effect of customer's regulatory focus orientation among in the relationships between service quality, perceived value, customer satisfaction and behavioral intention.

Research design, data, and methodology - This study intends to expand the existing service quality research by using the coffee shop service quality measurement tool developed by domestic researchers. I wanted to find some implications for the trend. In particular, this study applied the regulatory focus theory to identify individual differences of customers regulatory focusing motivation. In order to verify several hypotheses, the data were 227 college students and analyzed with SPSS/PC 21.0 and SmartPLS 3 program. The moderating role of customer's regulatory focusing motivation was tested using multi-group analysis with SmartPLS 3 program.

Results - The resutls are as follows. First, the fundamental characteristic factors only had a significant influence on the utilitarian value perception, but in the hedonic value perception, all other service factors except for the beverage characteristic had a statistically significant effect. Second, utilitarian and hedonic value had significant effects on customer satisfaction. Third, customer satisfaction had a significant effect on behavioral intention. Finally, the regulatory focus orientation played a moderating role in the relationship between beverage characteristic - utilitarian value, representation - utilitarian value, fundamental characteristic - hedonic value, physical environment - hedonic value, confidence - hedonic value, and utilitarian value - behavioral intention.

Conclusions - The results of this study show that the various service quality factors that make up the CoffeeSERV scale have different effects on utilitarian and hedonic value. This means that perceived benefits from product and service experience have different impacts on the customer's experience. Therefore, marketers should identify the impacts of service quality dimension that customers who use coffee shops consider important, understand the impact process of these quality factors on experience value, customer satisfaction, and behavioral intention, and allocate limited marketing budget. The results also show that it is possible to establish differentiatied response strategies using customer's regulatory focus orientation to find ways to enhance utlitarian and hedonic value, customer satisfaction, and behavioral intention using various Coffeeshop service quality factors. At the end of this paper, some limitations and future research directions were suggested.

Keywords: Coffeeshop, Service Quality, CoffeeSERV, Regulatory Focus Theory, Perceived Value, SmartPLS 3.0

JEL Classifications: L80, M10, M31.

\footnotetext{
* Lecturer, School of Business, Hankuk University of Foreign Studies, Email: kanghs10@hufs.ac.kr
} 


\section{1. 서론}

커피전문점은 특정의 제한된 장소에서 커피를 전문적으로 판매하거나, 음료, 술 또는 가벼운 식사까지 제공하는 곳을 말하며, 오늘날 커피전문점은 에스프레소를 기본으로 하여 20종류이상 음료 메뉴를 전문적으로 취급하면서 샌드위치, 베이글, 그리고 와플 같은 베이커리류를 판매하기도 한다.

20년 전에 등장한 국내 최초의 에스프레소 커피전문점인 할리스 커피와 스타벅스, 커피빈 등과 같은 글로벌 브랜드의 국내 진출로 인하여 활성화된 우리나라의 커피전문점은 이 미 한국의 대표적 외식산업의 일부로 인식되고 있으며, 전체 외식시장에서 차지하는 커피전문점의 비중과 시장규모는 지 속적으로 성장 추세에 있다.

현재 커피전문점시장은 대형 브랜드 중심으로 매장 수가 증가하면서 치열한 경쟁구도를 보이고 있으며, 경쟁우위를 차지하기 위하여 종업원의 질 높은 서비스를 포함한 차별화 된 서비스 품질을 제공하여 고객만족도를 제고시킬 필요성 이 매우 요구되고 있다. 이미 소비자들은 커피를 기호식품이 아닌 커피 구매를 통해 자기표현 욕구를 반영하여 삶의 질 을 추구하고자 하는 가치소비와 더불어 하나의 문화로 자리 매김 하고 있다 (Kim, Lee, \& Hwang, 2015). 따라서 커피전 문점은 단순히 커피만을 판매하는 장소가 아닌, 이미지나 분 위기를 팔 수 있는 물리적 공간으로서 다양한 가치체험을 하는 문화적 공간으로 변화하였으며, 소비문화의 아이콘으 로 인식되고 있다(Cho \& Lee, 2011). 이에 따라 커피전문점 들은 치열한 경쟁 환경에서 생존을 위한 효과적인 전략모색 을 통해 고객으로부터 외면당하지 않으려는 문제에 봉착하 고 있다(Choi, Koo, \& Lee, 2017).

현대는 경제에서 서비스가 차지하는 중요성이나 규모가 매우 커지고 있는 사회로서, 서비스 사회로 가는 원동력은 이전보다 다양해진 소비자의 욕구, 급속한 기술의 진보, 생 산 활동에서 서비스의 필요성 증대, 제품의 평준화와 같은 사회현상에 있으며(Lee, 2004), 특히 제품이 평준화되면서, 양질의 서비스를 제공하는 우수한 제품만이 경쟁에서 이길 수 있게 되었기 때문에, 현대의 기업들은 기업성과 향상을 위해 서비스 품질을 개선하고자 한다(Park \& Yoon, 2006).

본 연구는 커피전문점의 서비스품질이 고객의 지각된 가 치에 따라 고객만족과 행동의도에 미치는 영향을 살펴보고 자 하였다. 지금까지의 커피전문점 선행연구들은 서비스품 질을 커피전문점에 적용시키면서, 서비스품질과 고객만족, 서비스품질과 행동의도 등의 관계를 살피는 연구에 관심을 두고 있었으나(Kim \& Byun, 2010), 커피전문점의 서비스 품 질에 대한 지각된 가치에 근거한 고객만족과 관련된 연구는 미흡한 실정으로서(Kim \& Song, 2010), 커피전문점 서비스 품질에 대한 지각된 가치 연구는 커피전문점 브랜드의 마케 팅 전략 수립과 운영에 있어서 효과를 발휘할 것으로 예상 한다(Lee \& Kang, 2017).

우수한 서비스품질의 제공은 고객만족과 재구매의도를 높 일 수 있기 때문에 서비스품질의 측정을 통하여, 기업의 품 질 상태를 평가하고 이에 따라 서비스의 개선전략의 수립과 실천이 가 능해진다. 따라서 서비스품질의 측정은 높은 수준 의 서비스품질의 제공을 위해 중요한 요소라고 할 수 있다
(Park \& Yoon, 2006).

지금까지 커피전문점 서비스품질에 관한 선행연구들은 서 비스 산업에서 서비스품질의 측정에 이용할 수 있도록 개발 된 측정도구인 SERVQUAL(Parasuraman, Zeithaml, \& Berry, 1988), SERVPERF(Cronin \& Talor, 1992) 등을 사용하여 서 비스 품질을 측정하였다. SERVQUAL은 서비스품질을 서비 스 제공기업에 대한 고객의 기대와 서비스 성과간의 차이에 의해 결정된다는 Parasuraman et al.(1985)의 정의를 바탕으 로 개발하여 고객의 기대와 서비스 성과 간의 차이를 측정 하고자 하였으며, SERVPERF는 Cronin and Talor(1992)가 서비스품질을 고객 성과만으로 측정하는 척도의 효과성을 증명하면서 개발하였다.

한편, 서비스 산업은 해당 산업마다 고 유한 서비스 분 야 가 있으 므로, 이를 고려한 척도의 적용이 요구된다(Lee \& Lee, 1997). 그러나 SERVQUAL 과 SERVPERF와 같은 측 정도구들은 외식산업의 특성인 음식의 맛과 질, 다양성, 일 관성, 영양 등 음식에 관한 사항들을 측정하기에는 적 절하지 않은 것으로 평가 되었다(Yoo \& $\mathrm{Kim}, 2004)$.

본 연구에서는 커피전문점의 서비스품질을 측정하기 위하 여 국내 연구진에 의하여 개발된 CoffeeSERV(Park \& Yoon, 2006)를 측정도구로 선 택하여 커피전문점 서비스품질이 지각 된 가치에 따라 고객만족과 행동의도에 미치는 영향관계에 대해 살펴보고자 하였으며, 이러한 변수들 간의 영향관계에 서 고객의 개인 성향차이가 조절적 영향을 미치는 지를 알아 보고자 하였다. 조절초점동기이론에서는 향상초점(promotion focus)성향의 고객은 이 익에, 방어초점(prevention focus)성향 의 고객은 손실에 더 욱 민감하다고 하였다(Higgins, 1997). 따라서 향상초점의 고객과 방어초점의 고객은 동일한 서비 스품질에 대하여 다 른 인식과 반응을 보일 수 있을 것으로 예상할 수 있다. 본 연구는 이를 확인하기 위하여 향상초점 과 방어초점으로 고객집단을 구분하여 두 집단 간의 결과차 이를 검증하고자 하였으며 실증연구를 실시하여 그 결과를 분석하고 시사점을 검토하였다.

\section{2. 이론적 배경}

\section{1. 서비스 품질과 CoffeeSERV}

서비스품질은 특정 서비스의 우수성과 관련한 개인의 주 관적 평가 (Parasuraman et al., 1988)로서, 고객의 서비스에 대한 사전 기대치와 실제로 지각한 서비스 성과에 대한 고 객의 지각(Grönroos, 1984)이라고 정의할 수 있다. 품질은 제품의 구성성분이나 특정 성분의 차이로 나타나는 객관적 (Objective) 품질과 브랜드, 이미지, 광고 등에 의한 간 접적 평가인 지각된(Perceived) 품질로 구분할 수 있는 데(Mitra \& Golder, 2006), 이때 지각된 품질은 소비자가 주관적으로 인 식하는 것이며(Garvin, 1987), 소비자가 서비스품질에 대해 객관적으로 또는 획일적으로 규정할 수 있는 것이 아닌 서 비스가 제공되는 과정에서 경험하는 기대, 지각, 만족과 관 련된 복합적인 개 념이라고 할 수 있다 (Brady \& Cronin, 2001; Park, Oh, \& Hong, 2011) 
서비스품질은 무형성의 특성을 가지고 있어 객관적으로 측정하기 어 렵기 때문에, 고객은 서비스에 대한 경험과 서비 스와 관련된 유형적 단서를 바탕으로 특정 서비스를 지각하 며 이때 지각한 서비스와 사전에 기대한 서비스를 비 교하여 서비스 품질을 평가한다. 한편 서비스품질은 고객만족을 강 화하기 위한 수단으로서 기업의 수 익성 증가와 시장에서의 경쟁우위를 차지하기 위한 가치 있는 도구로 사용 될 수 있 다(Sivadeas \& Prewitt, 2000).

지금까지 서비스품질을 측정하는 도구로 SERVQUAL (PZB, 1988)과 SERVPERF(Cronin \& Taylor, 1992) 등의 모형 이 주로 사용되었다. PZB(1988)에 의해 제 안된 SERVQUAL 모형에서 지각된 서비스품질은 '서비스의 우수성과 관련된 전반적인 판단이나 태도 '로 정의되며, 신뢰성(reliability), 응 답성(responsiveness), 공감성(empathy), 확신성(assurance), 유형성(tangibles) 등 5 개의 차원으로 구성된다(Lee \& La, 2011). 한편 Cronin and Taylor(1992)는 지각된 서비스품질 의 기대를 제외한 성과만을 측정하는 SERVPERF를 개발하 였는데, 이들은 SERVQUAL이 사전 기대 측정이라는 개 념의 모호성으로 인하여 객관화가 어려우며, 서비스품질 경험 시 이미 과거의 기대가 반영되었기 때문에 성과 항목만으로 서 비스품질을 평가해야 한다고 주장하였다(Lee \& Lee, 2001).

한편 Grönroos(1984)는 서비스품질을 기능적 품질과 기술 적 품질로 구분하였다. 기술적 품질은 서비스를 통해 실제로 제공되는 품질로 객관적 측정이 가 능하지만, 기능적 품질은 서비스가 제공되는 방법과 관련하여 종업원들과의 상호관계 에 따라 영향을 받기 때문에 주관적인 평가일 수 밖에 없다. 따라서 기술적 품질은 결과에 초점이 맞춰진 것이며, 기능적 품질은 과정에 초점을 맞춘 차원으로 전자는 결과품질, 후자 는 과정품질로 불리우기도 한다.

지금까지 선행연구들은 과정품질을 중심으로 서비스품질 을 평가하였기에, 물리적 환경평가에 대한 비중은 상대적으 로 낮게 처리하였고, 과정품질과 결과품질은 중 복된다고 주 장하기도 하였다 (Llosa, Chandon, \& Orsingher, 1998; Lee \& Lee, 2001). 이에 대하여 Brady and Cronin(2001)은 기존 의 서비스품질 모 델을 보 완하면서, 소비자와 종업원간의 상 호작용 품질, 제공된 서비스 품질 지각에 대한 결과품질, 서 비스 제공 환경에 대한 물리적 환경품질 등 3 가지 품질 모 형을 제시하기도 하였다. 우수한 품질의 서비스 제공은 고객 만족과 재 구매의도를 높일 수 있고, 서비스품질 측정을 통 하여 현재의 품질 상태를 평가할 수 있으며, 이를 통해 서비 스의 개선과 강화전략을 수립할 수 있다. 따라서 높은 수준 의 서비스품질을 제공하기 위해서는 서비스품질의 측정은 중요한 요소라고 할 수 있다.

그러나 지금까지 사용하고 있는 서비스품질 측정도구들인 SERVQUAL이나 SERVPERF 등은 외식산업의 특성을 반영 한 서비스품질을 제대로 측정할 수 없었다는 주장이 있었다 (Yoo \& Kim, 2004). 즉, 커피전문점의 본원적 서비스인 음 식에 대한 문 항이 부족하였기 때문에 타당도가 낮았으며 (Park \& Yoon, 2006), 또한 서비스 산업은 해당 산업마다 고유한 서비스 분 야가 있기 때문에 이를 고려한 척도의 개 발이 필요하다는 의 견이 제기되었고(Lee \& Lee, 1997), 이 에 따라 Park and Yoon(2006)은 커피전문점에서 보 편적으
로 사용할 수 있는 객관적인 서비스품질 측정도구로 CoffeeSERV를 개발하였다.

Park and Yoon(2006)은 커피전문점에서 사용할 수 있는 서비스품질 측정도구를 개발하기 위하여 서 울의 S대학교내 의 에스프레소 커피전문점 이용고객들을 대상으로 2차에 걸 쳐 설문문항 개발을 위한 설문조사와 전문가 인터뷰, 기존 연구를 바탕으로 문 항을 개발하였으며 이에 대한 신뢰도 분 석과 요인분석을 반 복 실시하여 최종적인 5 개 차원의 21 개 문항을 개발하였고, 이를 CoffeeSERV라고 명명하였다.

따라서 CoffeeSERV는 지금까지 외식산업의 서비스품질 을 측정하는 도구로 사용한 SERVQUAL(PZB, 1988) 등이 외식산업의 서비스 품질에서 중요한 요소인 음식의 맛과 질, 다양성, 일관성, 영양 등과 같은 음식에 관한 외식산업의 특 성을 반영한 서비스품질을 제대로 측정할 수 없었던 한계 (Yoo \& Kim, 2004)를 극복하고 국내 에소프레소 커피전문 점에서 사용할 수 있는 신뢰성과 타당성이 확보된 서비스품 질 측정 척도라고 할 수 있다. 본 연구에서는 CoffeeSERV를 측정도구로 사용하여 커피전문점 서비스품질이 지각된 가치, 고객만족, 행동의도에 미치는 영향관계와 이 구성변수들 간 의 관계에 고객의 조절초점 동기성향이 조절적 영향을 주는 지를 살펴보고자 하였다.

\section{2. 지각된 가치}

가치란 소비자의 상이한 행동영역들을 설명하는 변수로서 소비자의 시간, 금전, 노력 및 감정적 투입에 대한 보상의 정도로 이해할 수 있으며, 또한 가치는 사 람들이 대상에 대 해 갖는 신념이며 동기부여의 목표로서 특정 대상에 대한 태도가 형성되고 행동으로 연 결되는 과정에서 내재되는 것 이라고 할 수 있다 $(\mathrm{Kim} \&$ Won, 2005).

Zeithaml(1988)은 가치를 혜택(benefit)과 희생(sacrifice)간 의 교환으로 보고, 가치의 지각은 제품이나 서비스에 대하여 지불한 것과 획득한 것에 대해 고객이 내리는 전반적인 평 가라고 정의하였으며, Schechter(1984)는 지각된 가치가 구 매자의 경험을 형성하는 객관적이고 주관적인 요인 뿐 아니 라 질적이고 양적인 요인들로 구성되어 있다고 설명하였다.

한편 지각된 가치는 고객이 제품이나 서비스를 사용하는 상황에서 발생하는 제품, 서비스의 속성이나 결과에 대해 지 각한 선호도와 평가로서 고객가치라고도 하며(Woodruff, 1997), 고객가치는 고객이 제품과 서비스에서 획득할 편익 과 지불 비용간의 차이를 경쟁사와 비 교한 결과로 표현되기 도 한다(Kotler \& Armstrong, 2008). 그리고 Holbrook(1994) 은 고객가치는 가치창출이나 소비경험을 유발하는 제품과 서비스와의 상호작용에 따 른 교환활동을 통해 이 루어진다고 하였다. 따라서 고객가치는 생산된 제품이나 서비스를 사용 한 후 느끼는 제품의 효용성이나 서비스 만족을 경험한 후 고객과 공급자 간에 형성된 감정적 결속이라 정의할 수 있 을 것이다(Butz \& Goodstein, 1996).

Babin, Darden, and Griffin(1994)은 가치를 구 조상 실용적 가치(Utilitarian value)와 쾌락적 가치 (Hedonic value)로 구분 하였으며, 개인의 소비행동에서 소비경험이 실용적 측면과 쾌락적 측면의 결과를 야기한다고 주장하였다. 실용적 가치 
는 제품에 대한 소비자의 지각된 품질과 기대성과에서 발생 된 유용성(Sweeney \& Soutar, 2001)이며, 서비스의 품질과 성과가 기대 이상으로 높게 지각 될 때 실용적 가치에 대한 만족 감을 얻게 된다. 또한 감정적 가치는 제품으로부터의 정서적 상 태나 느낌이 만들어 내는 유용성이라고 할 수 있으며(Sweeney \& Soutar, 2001), 소비자가 제품이나 서비스에 대해 긍정적인 느낌을 가질 때 감정적 가치에 대한 만족감은 높아진다.

고객가치에 대한 연구는 효용성과 실용성을 중심으로 연 구가 이 루어졌으나, 1990 년 이 후로 실용적 가치와 더불어 쾌락적 가치가 부각되기 시 작하였으며, 실용적 가치에 쾌락 적 가치를 고려하는 연구가 이루어 졌다(Kim, 2011). 따라서 실용적 가치는 계 획하였던 목표를 의식적으로 추구함으로써 얻게 되지만, 쾌락적 가치는 감정적인 즐거움을 나타내는 것 으로서(Kim, 2012), 쾌락적 차원의 소비경험은 제품이나 서 비스의 독특성, 상징적 의미, 감정적 상기 그리고 환기된 이 미지라고 할 수 있다 (Holbrook \& Hirschman, 1982). 한편 Lee, Kim, and Jeong(1999)은 백화점에서 쇼핑하고 나온 고 객을 대상으로 쇼핑만족에 대해 실용적 가치와 쾌락적 가치 를 접목한 구 조 모델을 검정하기도 하였는데, 실용적 소비자 들은 소비활동을 합리적이고 의 무적인 형태로 행하며, 소비자 들은 계 획적이고 효 율적인 소비활동을 하기 위해 가치의 실 용적인 차원에 중심을 두게 된다고 하였다(Lee et al., 1999).

과거 연구자들은 소비자가 소비활동을 통해 가치를 얻을 시 실용적인 측면에만 중점을 두고 소비활동을 행한다는 것에 관심을 두고, 실용적 측면인 실용적 가치만을 소비자행동의 중요한 요소로 간 주하고 연구를 진행하였다 (Batra \& Ahtola, 1991; Hanzaee \& Rezaeyeh, 2013). 그러나 Woods (1960)는 제품에 대한 소비자 수요의 발생을 자아관여 (ego-involvement) 차원과 쾌락적(hedonic), 기능적(functional) 차원에서 보 았으 며, 자아관여 차원은 외적 상 징의 기 능을 수행하는 제품에 대한 수요로 발현된다고 하였다. 또한 쾌락적 차원의 제품들 은 주로 감각적, 정서적 목적, 혹은 재미와 즐기기 위한 목적 에서 소비되지만, 실용적, 기능적 차원의 제품들은 합리적이며 이성적인 차원에서 평가되고 소비되기 때문에 (e.g., Holbrook, 1986; Woods, 1960), 제품은 쾌락적 또는 실용적 소비 목적에 부합되게 사용되며, 소비행위 또한 쾌락적이거나 실용적인 동 기에 의해 유발된다고 할 수 있다 (e.g., Hirshman \& Holbrook, 1982; Hirshman, 1986)고 하였다. 한편 $\operatorname{Kim}(2012)$ 은 소비자 들은 외식업체를 방문하는 경우 합리적 또는 쾌락적 욕구를 채우려고 하며, 이때 외식을 통하여 실용적 동기와 감정적인 혜택을 받으려는 쾌락적 동기가 반영된다고 제 안하였다.

\section{3. 조절 초점 이론}

Higgins(1997)에 의해 제 안된 조절초점동기이론은 개인의 내재된 특성에 따라 사람들은 자 신의 목표를 충족시키는 행동 유형을 향상초점 동기와 방어초점 동기라는 두 가지의 동기구 조로 구분할 수 있다고 하면서 조절초점(regulatory focus)이 라는 개 념을 사용하여 설명한 이 론이다. Higgins(1997)에 따 르면 사 람들은 쾌락은 추구하고 고통은 회피하려는 동기를 가지고 있으며, 성취하고 싶은 목표를 설정할 때 목표에 대 해 자신의 행동에 부합하려고 하는데, 자신의 목표를 달성하
는 과정에서 향상초점동기와 방어초점동기와 같은 행동 유형 이 나타나며 이것은 개인의 생각, 감정, 행동과 의사 결정에 영향을 미친다고 하였다.

따라서 향상초점 동기는 현재의 상 황을 만족스럽고 원하 는 결과로 향상시키려는 상태를 지향하며, 예방초점 동기는 불만족스럽거나 원하지 않는 결과로 변화하는 것을 방지하 고자 현재의 상태를 유지하려는 목표를 가지는 것을 의미한 다(Higgins, 1997). 이처럼 향상초점 동기는 진취적 성향을 가지며 성취, 향상, 증진, 열망과 같은 욕구를 반영하고 새 로운 상 황에 대한 도전적인 의식이 드 러나는 반면, 예방초점 동기는 회피적인 성향으로 안전, 책임, 보호, 방어와 같은 욕구가 있고, 새로운 상 황에 대해서는 소 극적 회피적인 의식 이 드러난다(Higgins, Shar, \& Friedman, 1997).

Higgins(1997, 1998)의 연구에 의하면, 향상초점의 사 람들 은 강한 자아와 애정 어 린 관심의 욕구가 더욱 강하고 획득 -무획득의 상 황에 놓일 가 능성이 높으며, 강한 자아를 가지 고 있는 사람들로서, 존재하는 것과 긍정적인 결과의 부재에 민감하게 반 응하는 반면, 예방 초점의 사람들은 안전에 대한 욕구가 높고, 강한 의 무감과 손실-무손실 환경에 놓였을 가 능성이 높은 사람들로서 부재와 부정적 결과의 존재에 대해 민감하게 반 응한다고 하였다(Higgins, 1997, 1998). 또한 Higgins(1998)는 조절초점은 개인에게 내재한 특성이기도 하 지만 상 황에 따라 유발될 가능성도 있으며, 내재한 조절초점 은 사회화 과정에서 겪은 각기 다 른 학습방법과 가치들에 영향을 받은 것이고, 상황에 따라 유발되는 조절초점은 제품 의 특성에 영향을 받는다고 하였다.

Ko et al.(2012)은 제품 유형과 연관성을 연구하면서 향상 초점동기 성향의 소비자는 감정적인 정보 처리를 하며, 예방 초점동기 성향의 소비자는 체계적인 정보 처리를 한다는 점 에 근거하여 쾌락재와 실용재간의 추구성향이 다 르게 나타 날 것이라는 가 설을 바탕으로 실험을 실시하기도 하였는데, 연구 결과, 향상초점 소비자는 쾌락재를, 방어초점 소비자는 실용재를 더 욱 선호한다는 것을 확인하였다. 이는 제품군과 조절초점과의 적합성을 발 견한 연구라고 할 수 있다.

\section{3. 연구 방법}

\section{1. 연구모형}

본 연구는 커피전문점 서비스품질 측정 도구인 CoffeeSERV (Park \& Yoon, 2006)을 적용하여 커피전문점 서비스품질이 가치지각과 고객만족, 행동의도에 미치는 영향을 살펴보면서 소비자의 조절초점동기 성향이 서비스품질과 변수들의 영향 관계에 조절적 역할을 하는지를 검증하려는 연구 목적에 따라 <Figure 1>과 같이 연구모형을 설정하였다.

\section{2. 연구가설 설정}

\subsection{1. 커피전문점 서비스품질과 지각된 가치간의 관계}

Park and Yoon(2006)은 커피전문점의 서비스품질을 측정 
하기 위하여 신뢰감, 커피의 본원적 특성, 물리적 환경, 커 피의 본원적 특성 외 음료의 특성, 대표성과 같이 5 개 요인 의 21 개 문항으로 이루어진 CoffeeSERV 측정모형을 개발하 였으며, CoffeeSERV의 5 가지 차원은 커피산업의 특성 상 음식의 맛과 질, 다양성, 일관성, 영양 등 음식에 관한 사항 들로서 커피전문점의 서비스 품질을 측정하기 위해서는 중 요한 요소라고 할 수 있다.

본 연구에서는 CoffeeSERV의 5 개 차원의 서비스 품질이 고객들의 지각된 가치에 유의한 영향을 미 칠 것으로 예상하 였다. 서비스품질에 관한 선행연구들은 서비스품질 평가차 원 요소들이 고객의 자각된 가치를 증대시 킨다고 하였으며 (Kwun, 2011; Chen \& Hu, 2010), Lee(2007)의 연구에서도 레스토랑에서의 서비스품질이 지각된 가치에 유의한 영향을 미치기 때문에 높은 서비스품질은 고객 자 신이 투자한 유무 형적 비용대비 가치를 높게 평가한다고 보고하였다. 본 연구 는 선행연구를 통하여 확인한 고객의 지각된 가치를 실용적 가치와 쾌락적 가치 측면에서 상호 영향관계를 고 찰하고자 하였으며, 다음과 같이 가설 < $\mathrm{H} 1>$ 과 < $<2>$ 를 설정하였다.

\section{H1: 커피전문점의 서비스품질은 소비자의 실용적 가치 지각 에 정 $(+)$ 의 영향을 미칠 것이다.}

H1-1: 커피전문점의 본원적 특성은 소비자의 실용적 가치에 유의한 영향을 미칠 것이다.

H1-2: 커피전문점의 물리적 환경은 소비자의 실용적 가치에 유의한 영향을 미칠 것이다.

H1-3: 커피전문점의 신뢰감은 소비자의 실용적 가치에 유의 한 영향을 미칠 것이다.

H1-4: 커피전문점의 본원적 특성외의 음료의 특성은 소비자 의 실용적 가치에 유의한 영향을 미칠 것이다.

H1-5: 커피전문점의 대표성은 소비자의 실용적 가치에 유의
한 영향을 미칠 것이다.

\section{H2: 커피전문점의 서비스품질은 소비자의 감정적 가치 지각} 에 정(+)의 영향을 미칠 것이다.

H2-1: 커피전문점의 본원적 특성은 소비자의 감정적 가치에 유의한 영향을 미칠 것이다.

H2-2: 커피전문점의 물리적 환경은 소비자의 감정적 가치에 유의한 영향을 미칠 것이다.

H2-3: 커피전문점의 신뢰감은 소비자의 감정적 가치에 유의 한 영향을 미 칠 것이다.

H2-4: 커피전문점의 본원적 특성외의 음료의 특성은 소비자 의 감정적 가치에 유의한 영향을 미칠 것이다.

H2-5: 커피전문점의 대표성은 소비자의 감정적 가치에 유의 한 영향을 미칠 것이다.

\subsection{2. 지각된 가치와 고객만족간의 관계}

소비자의 지각된 가치는 구매 전 선 택행동과 구매 후 만 족이나 재구매 의도, 그리고 추천에 직접적인 영향을 미친다 (Parasuraman \& Grewal, 2000)고 하였다. 따라서 소비자가 중요시하는 가치요소를 파악하여 경쟁보다 우위를 확보할 수 있다면 소비자의 행동의도를 유리하게 높일 수 있게 되 며(Hyun \& Han, 2009), 이 경우 소비자의 가치 지각은 고객 만족을 높여 주며 고객의 태도 형성에 긍정적인 영향을 미 칠 수 있다 (Kwun, 2011).

고객만족이란 구매한 특정 제품이나 서비스에 대한 쇼핑 이나 구매행동과 같은 개별적 행위에서 유발된 정서적 반 응 (Cho, Chang, \& Chae, 2012), 또는 기대와 욕구에 부 응하 여 획득한 경험품질 전반에 대해 갖게 되는 감정적 태도로 정의(Cole \& Scott, 2004)할 수 있다. 고객들은 제품이나

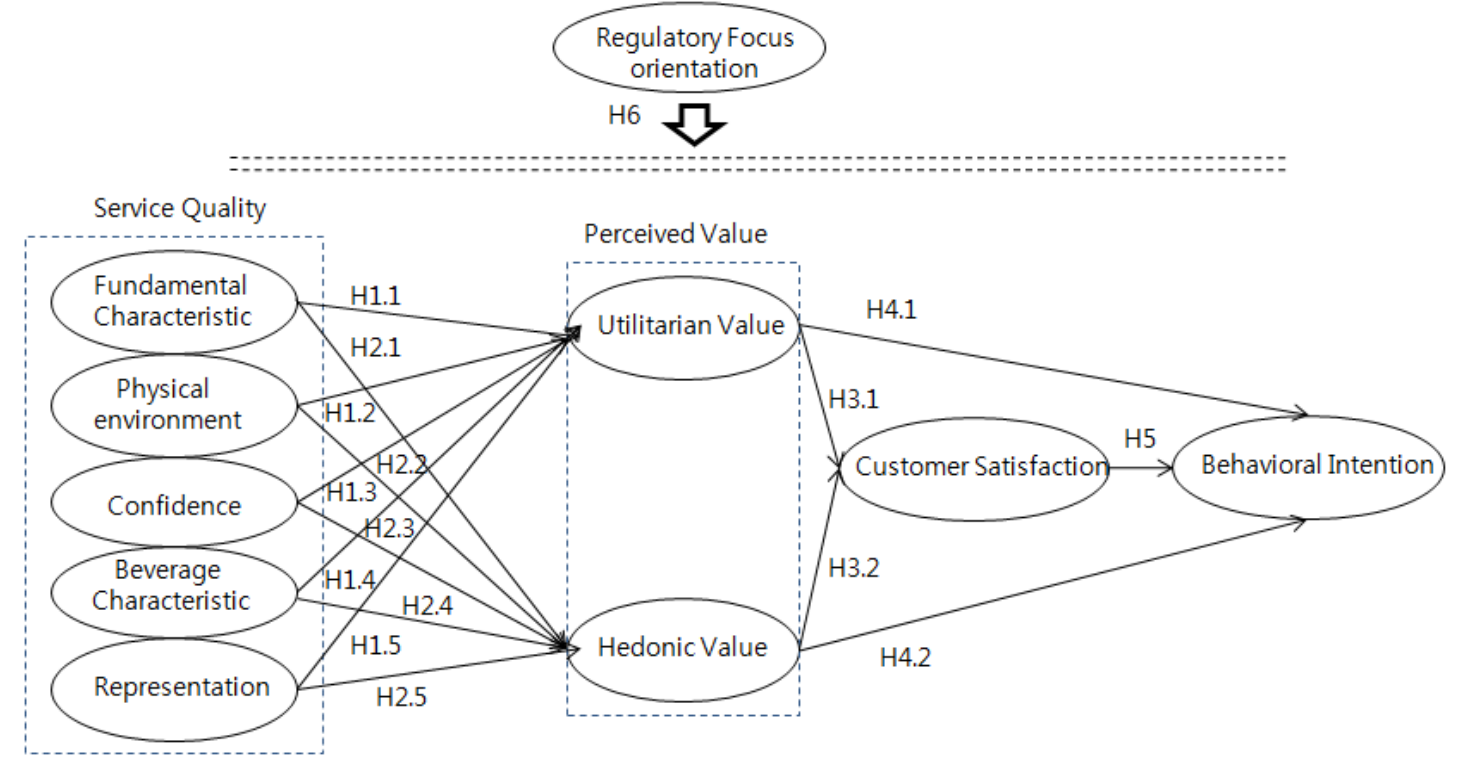

Figure 1: Hypothesized model 
서비스 이용에서 만족하는 경우 좋은 감정을, 반대로 불만족 한 경우에는 불 쾌한 감정을 주위에 알리는 행동을 하 므로 고객만족은 매우 효 율적인 마케팅 도구라고 할 수 있다 (Dubroski, 2001).

이처럼 고객만족에 대한 정의는 고객만족의 관점에 따라 결과와 과정으로 나 누어서 살펴 볼 수 있는데(Choi \& Jun, 2007), 고객이 치른 대가에 대한 적절 혹은 부적절하게 보상 받 았다고 느끼는 인지적 상태 (Howard \& Sheth, 1979)로 정의하 거나, 불일치의 기대로 인한 감정이 고객의 구매 경험 전 감정 과 결합될 때 발생하는 종합적인 심리적 상태(Oliver, 1981)로 정의하는 것은 결과의 관점이며, 소비경험이 최소한 기대하였 던 것만큼 좋은 것이 되도록 조정된 평가(Hunt, 1977)로 정의 하는 것은 과정 관점에서의 정의라고 할 수 있다.

Babin et al.(1994)과 Jones, Reynolds, and Arnolds(2006) 는 고객의 실용적 가치와 쾌락적 가치 모두 고객만족도에 긍정적인 영향을 준다고 하였는데, 고객의 만족도는 실용적 가치보다는 쾌락적 가치가 높게 인지 될 때 높아진다고 두 연구 공히 제 안하고 있다. 또한 호 텔, 패밀리 레스토랑, 커 피전문점 등을 대상으로 한 선행연구에서도 고객의 가치지 각이 고객만족에 긍정적인 영향을 미치고 있다는 것을 보여 주었다(Hyun \& Han, 2009; Cho \& Kang, 2011). 이와 같은 선행연구를 바탕으로 다음과 같이 가설 < $\mathrm{H} 3>$ 을 설정하였다.

\section{H3: 소비자의 서비스 품질에 대한 지각된 가치는 고객만족 에 정 $(+)$ 의 영향을 미칠 것이다.}

H3-1: 소비자의 서비스 품질에 대한 실용적 가치 지각은 고 객만족에 유의한 영향을 미칠 것이다.

H3-2: 소비자의 서비스 품질에 대한 감정적 가치 지각은 고 객만족에 유의한 영향을 미칠 것이다.

\subsection{3. 지각된 가치와 행동의도간의 관계}

행동의도는 어떤 대상에 대해 태도를 형성하고 그에 따라 특정한 미래 행동으로 발생할 수 있는 개인의 의지와 신념 이라고 정의할 수 있으며(Zeithaml, Berry, \& Parasuraman, 1996), 일반적으로 재 방문과 추 천의도 등으로 측정하고 있 다(Chen, 2008; Varki \& Colgate, 2001).

재방문은 고객이 이용한 레스 토랑이나 커피전문점을 다시 방문하는 직접 재방문과 주변 사 람에게 추 천하거나 함께 방 문하는 것이라 할 수 있다 (Lee \& Suh, 2012). 재방문은 상 품과 서비스에 대한 고객의 만족에서 비 롯되며, 고객에게 우 수한 가치가 제공되었을 때 고객과의 호의적인 관계가 장기 화될 가능성이 커진다(Kandampully \& Duddy, 2001). 경쟁이 심할수록 고객의 재방문과 재구매를 유지하는 능력은 기업 의 성공을 보장할 수 있다(Kandampully \& Liam, 2001). 한 편 추천은 소비자 행동분야에서는 구전현상으로 연구되었으 며(Suh \& Lee, 2011), 주변사람에게 추 천하려는 구전 의향 의 정도로 정의할 수 있다(Lee, 2007).

지각된 가치와 행동의도의 관계를 고 찰한 선행연구들은 레스토랑, 호텔, 커피전문점 등을 대상으로 지각된 가치가 행동의도에 긍정적 영향을 미 친다고 제 안하고 있다(Chen \&
$\mathrm{Hu}, 2010)$. 또한 Moon and $\mathrm{Bae}(2013)$ 는 커피전문점을 대상 으로 고객이 지각한 사회적, 확신적 특별대우 등의 관계혜택이 지각된 가치와 만족도에 미치는 영향을 연구하였는데, 확신적 혜택이 지각된 가치에 긍정적 영향을 미치며, 이 가치지각은 고객만족에 긍정적 영향을 미치는 것을 확인하였다. 한편, Han and Hyun(2009)은 패밀리 레스 토랑의 가치 구성은 품질, 가격, 명성 등이며, 이는 고객만족 및 행동의도에 유의한 영향을 미 친다는 연구결과를 제 안하였고, Lee, Moon, and Choi(2012)은 패스트푸드점을 대상으로 한 연구에서 Sweeny and Soutar (2001)의 연구를 토대로 지각된 가치를 기 능적, 사회적, 감 정적 가치로 구성하여 기능적 가치와 감정적 가치가 고객만 족의 결과변수인 행동의도에 유의한 영향을 미치는 것을 밝 히고 있다.

본 연구는 이러한 선행연구를 바탕으로 커피전문점 서비스 품질에 대한 지각된 가치가 소비자의 행동의도에 긍정적 영향 을 미 친다고 가정하고 다음과 같은 가설 < $44>$ 를 설정하였다.

\section{H4: 소비자의 서비스 품질에 대한 지각된 가치는 행동의도 에 정 $(+)$ 의 영향을 미칠 것이다.}

H4-1: 소비자의 서비스 품질에 대한 실용적 가치 지각은 행 동의도에 유의한 영향을 미칠 것이다.

H4-2: 소비자의 서비스 품질에 대한 감정적 가치 지각은 행 동의도에 유의한 영향을 미칠 것이다.

\subsection{4. 고객만족과 행동의도간의 관계}

Oliver(1993)는 만족을 소비자가 자 신의 욕구를 충족한 수 준에 대해 판단하는 반 응이라고 정의하면서도 분 석 수준에 따 라 다양한 형태로 나타날 수 있음을 강조하였다. 즉 고객의 욕구를 충족하는 수준이 란 자신의 주관적인 평가라는 의미이 다. 만족을 느낀 고객이 매장을 재방문하는 경우, 외식업체의 수익성 확보에 도 움이 될 것이다. 반대로 불만족한 고객은 이 탈하거나, 부정적 구전행위를 통하여 손실을 초 래할 수도 있 다(Choi \& Jun, 2007). 행동의도는 고객이어 떤 대상에 대한 태도를 형성한 후 특정한 미래행동으로 나타내려는 개인의 의 지와 신념을 말하며 (Boulding, Kalra, \& Staelin, 1993), Fridgen (1991)은 만족한 레스토랑이나 유사 레스토랑 또는 디른 지 역의 동일 레스 토랑을 다시 방문하려는 의향으로 정의하고 있다. Lee, Park, and Park(2003)는 외식업체 서비스 품질, 고객만족, 재방문 의도 및 구전의도 간의 관계에서도 고객만 족과 재 방문의도 간에는 긍정적인 관계가 유의함을 확인하였 다. 본 연구에서는 고객만족은 행동의도에 대하여 긍정적인 영향을 가정하면서 다음과 같이 가설 <H5>를 설정하였다.

\section{H5: 고객만족은 행동의도에 정(+)의 영향을 미칠 것이다.}

\subsection{5. 서비스품질과 지각된 가치, 고객만족, 행동의도의 관} 계에서 조절초점동기 성향의 조절적 영향

본 연구는 CoffeeSERV 측정 모형의 5 가지 차원이 고객 의 실용적 가치와 감정적 가치에 대한 지각, 고객만족, 행동 의도에 미치는 영향은 고객의 개인차에 따라 다르게 발생할 
것으로 예상하였다. 즉 조절초점 동기는 조절적 적 합성 (regulatory fit)의 개 념을 따라 커피전문점 서비스품질이 가치 지각과 그 외 변수들에 영향을 주는 과정에서 차별적 역할을 수행할 수 있으며, 따라서 커피전문점 서비스품질과 고객의 가치지각, 고객만족, 행동의도에 미치는 영향관계는 고객의 조절초점동기성향에 따라 다르게 나타날 것으로 예상하였다.

조절초점 동기이론에서는 사 람들은 고통을 회피하고 쾌락 을 추구하려는 동기를 가지고 있으며 이 러한 동기는 개인의 목표지향에 따라 자 신의 행동을 향상초점과 예 방초점으로 조절하게 된다(Higgins, 1997)고 하였다. 따라서 예 방초점 관 련된 동기가 두드 러지는 상 황이나 조건에서 더 욱 민감하게 나타나는 가치지각은 감정적 가치보다는 실용적 가치에 대 한 반 응이 더 크게 나타날 것으로 예상할 수 있다. 실용적 가치는 제품에 대한 소비자의 품질 지각과 기대에 대한 유 용성이 발생하는 것으로 정의할 수 있으며(Sweeney \& Soutar, 2001), 제품이나 서비스에 대한 품질이나 성과가 기 대 이상으로 지각될 때 실용적 가치에 대한 만족감이 발생 하게 된다. 그러므로 실용적 가치를 중시하는 소비자는 실용 적 기능을 충족하는 제품을 선 택하고자 실용적 가치를 보다 더 긍정적으로 판단할 것이다. 한편 감정적 가치지각은 제품 이 가진 정서적 상태 또는 느낌에 대한 유용성 지각을 말하 며, 소비자들은 소비경험을 통해 경험하는 감정적 혜택에 따 라 구매의사가 결정될 수 있다. 이처럼 감정적 가치는 제품 이나 서비스에 대해 가지는 긍정적인 느낌에 따라 지각되며 감정적 가치는 소비자로 하여금 비인지적이고 무의식적인 동기에 의한 선 택행동을 하도록 영향을 미칠 수 있다. 따라 서 향상초점동기성향의 소비자들은 제품을 소비한 경험을 바탕으로 편안, 안전, 흥분, 애정 등 제품과 서비스로부터 느끼는 감정적 요인에 의한 감정적 가치를 실용적 가치 보 다 더 크게 지각할 것으로 예상할 수 있다. 따라서 선행연구 를 바탕으로 다음과 같이 가설 <H6>를 설정하였다.

\section{H6: 소비자의 조절초점동기성향은 커피전문점 서비스품 질, 지각된 가치, 고객만족, 행동의도의 영향관계에 대한 조절효과가 있을 것이다.}

\section{3. 변수의 정의 및 측정}

모든 문항들은 Likert 7점 척도(1점; 매우 그 렇지 않다, 7 점; 매우 그 렇다)를 이용하여 측정하였으며, 본 연구에 사용 한 변수들의 조작적 정의는 다음과 같다.

커피전문점 서비스품질은 커피전문점을 방문하는 고객들이 지각하는 서비스의 총합으로 정의된다. 커피전문점 서비스품질 은 외식산업의 서비스품질 특성인 음식의 맛과 질, 다양성, 일 관성, 영양 등 음식에 관한 것들을 반영한 커피전문점 서비스 품질 측정도구인 CoffeeSERV(Park \& Yoon, 2006) 척도에서 사용된 5 개차원 (본원적 특성, 물리적환경, 신뢰감, 커피의 본원적 특성외 음료의 특성, 대표성)의 21 개문 항을 이용하여 측정하였다.

지각된 가치는 Grewal et al.(1998)과 Sweeney and Soutar (2001)의 연구에서 다차원적 접근방법으로 사용한 척도를 토대로, 지각된 가치를 실용적 가치와 감정적 가치로 구분하 여 연구한 선행연구(Choi, Ahn, \& Lee, 2015)에서 각각 4개
항목을 선정하여 측정하였다.

고객만족은 커피전문점의 바리스타에 대한 만족, 분위기에 대한 만족, 메뉴에 대한 만족, 커피전문점의 전반적인 만족 등 4개 문 항으로 측정되었다(Cheon, Hong, \& Kim, 2013).

행동의도는 특정 대상에 대한 태도 형성과 그로 인한 미 래 행동을 나타내는 개인의 의지와 신념으로 정의된다 (Zeithaml, Berry, \& Parasuraman, 1996). 본 연구에서는 행 동의도를 Cheon et al. (2013)의 연구에서 사용한 재 방문, 점포 충성도, 추천 등 4 개 항목으로 측정하였다.

개인의 조절초점동기성향은 Higgins et al.(2001)의 기질 적 조절초점(Higgins et al., 2001)의 조절초점설문항목 (RQM: Regulatory Focus Questionnaire)을 국내연구에서 검 증하여 사용한 11 개 문 항(Oh, 2015)으로 측정되었다. 향상 초점과 예 방초점을 나 누기 위한 분 석은 각각의 문 항에 대한 평균값의 차이를 이용하여 기질적 조절초점을 구분하는 중 위치 분리법(median split method)을 활용하여 응답자들의 향상초점과 방어초점 성향을 구분하였다. Conover(1980)는 표본이 균등하게 분 배되지 않을 경우 $\mathrm{t}$-test가 항상 강력한 것은 아 니므로 mann-whitney test가 타당하지 않는 상 황에 서는 중 앙치 검정(median test)이 적용되어질 수 있다고 하 였다(Conover, Wehmane, \& Ramsey, 1980).

\section{4. 실증 분석}

\section{1. 표본설계 및 분석방법}

본 연구의 목적을 달성하기 위하여, 서울 소재 $\mathrm{H}$ 대학교 학부생을 대상으로 판단표본추출방법을 이용하여 설문조사 를 실시하고 데이터를 수 집하였다. 대학생들은 커피전문점 의 주 이용자일 뿐만 아 니라, 핵심고객층이라 할 수 있어서 본 조사의 대상자로 적 절하다고 판단된다. 총 240 부의 설문 지를 배부하여 커피전문점 이용 경험 여부를 확인한 후 경 험자만을 조사에 참여시켜 설문을 작성하게 한 후, 결측값이 있거나 불성실하게 응답한 설문지를 제외한 유효표본 총 227 부를 가 설 검증을 위한 데이터로 활용하였다. 수집된 데 이터는 SPSS 21.0과 SmartPLS 3.0 통계패키지를 이용하여 분석하였다. 모형의 적 합도 및 타당도, 신뢰도는 요인분석, 상관관계 분 석, 신뢰도 분 석을 이용하여 검증하였으며, 연구 모형은 구 조방정식 모형 분 석을 이용하여 검증하였다.

\section{2. 표본의 일반적 특성}

본 연구의 유효표본(N=227)의 빈도분석의 결과는 <Table $1>$ 과 같다. 응답자는 남학생 $(54.6 \%)$ 이 여 학생 (45.4)보다 다 소 많았으며, 연령대는 대부분 20 대 초.중반이며 $(92.9 \%)$, 커 피전문점 방문은 주 2 회(41.0\%), 주 4 회 이상 $(25.6 \%)$ 이 주로 많았다. 또한 응답자의 개인 성향의 차이를 알아보기 위해 기질적 조절초점 동기조사를 통해 예 방동기성향 고객 집단(120명, 52.9\%)과 향상동기성향집단(107명, $47.1 \%)$ 으로 구분하였다. 
Table 1: Demographic Profile

\begin{tabular}{|c|c|c|c|}
\hline \multicolumn{2}{|r|}{ Characteristics } & (n) & (\%) \\
\hline \multirow{2}{*}{ Gender } & Male & 124 & 54.6 \\
\hline & Female & 103 & 45.4 \\
\hline \multirow{4}{*}{ Age } & 18 22 years old & 45 & 19.8 \\
\hline & 23 26 years old & 166 & 73.1 \\
\hline & $27 \sim 30$ years old & 15 & 6.6 \\
\hline & over 30 years old & 1 & 0.4 \\
\hline \multirow{5}{*}{$\begin{array}{l}\text { Monthly } \\
\text { income }\end{array}$} & 500,000 won below & 92 & 40.5 \\
\hline & $500 \sim 700,000$ won over & 66 & 29.1 \\
\hline & $700 \sim 1,000,000$ won & 42 & 18.5 \\
\hline & $1,000,000$ won over & 23 & 10.1 \\
\hline & etc. & 4 & 1.7 \\
\hline \multirow{6}{*}{$\begin{array}{l}\text { Visiting } \\
\text { count }\end{array}$} & Once per week & 30 & 11.9 \\
\hline & twice or thrice per week & 93 & 41.0 \\
\hline & beyond four per week & 58 & 25.6 \\
\hline & once per month & 8 & 3.5 \\
\hline & $2 \sim 3$ per month & 23 & 10.1 \\
\hline & At least once every day & 18 & 7.9 \\
\hline \multirow{6}{*}{$\begin{array}{l}\text { Preference } \\
\text { store type }\end{array}$} & global large size & 87 & 38.3 \\
\hline & domestic large size & 12 & 5.3 \\
\hline & domestic small size & 20 & 8.8 \\
\hline & small size near school & 46 & 20.3 \\
\hline & non Specific brand & 56 & 24.7 \\
\hline & etc & 6 & 2.6 \\
\hline \multicolumn{2}{|r|}{ total } & 227 & 100.0 \\
\hline
\end{tabular}

\section{3. 측정항목의 신뢰도 및 타당성 검정}

본 연구에서는 SmartPls 3.0 을 이용하여 다 항목으로 구 성된 연구 단위들의 단일 차원성을 분 석하였다(Hair, Hult, Ringle, \& Sarstedt, 2016; Kim, Kim, \& Lee, 2019). 우선, Cronbach's $\alpha$ 와 연구단위 신뢰도(composite reliability: $\mathrm{CR}$ ) 를 이용하여 연구 대상의 내적 일관성을 측정하는 신뢰성을 확인한 결과, <Table 2>와 같이, 연구단위인 신뢰성, 본원적 특성, 물리적 환경, 음료특성, 대표성, 고객만족, 행동의도, 실용적 가치와 감정적 가치 등에 대한 Cronbach's $\alpha$ 값은 각각 $.955, .909, .859, .776, .751, .912, .940, .938, .815$, CR값은 $.963, .937, .904, .860, .843, .938, .957, .955, .873$ 으로 분 석되어 일반적으로 요구되는 기준인 .70을 초과하여 측정항목들 간의 신뢰성이 높은 것으로 나타 났다.

다음으로 개 념타당성을 측정하기 위하여 집중타당성과 판 별타당성을 살펴본 결과, <Table 2>에서와 같이, 동일한 개 념 간의 높은 상관관계로 평가되는 집중타당성은 각 요인에 적재된 요인적재값이 .60 이상이며, AVE 값이 .50 이상으로 나타나, 각 연구 단위들의 집중타당성이 입증되었다. 또한 상이한 개 념간의 낮은 상관관계로 평가되는 판별타당성은 $\mathrm{AVE}$ 의 제 곱근(square root) 값이 상관관계 값보다 크면 판 별타당성이 있는 것으로 설명되는데, <Table $3>$ 와 같이 Fornell-Larker 기준을 살펴 본 결과, AVE 값의 제 곱근 값이 상관관계 계수 값보다 크며, 쌍을 이 룬 연구 단위들 간의 상 관관계 값의 자 승 값이 AVE 값보다 작은 것으로 나타나 각 연구 단위들 간의 판별타당성이 입증되었다.

Table 2: Measurement items and validity assessment

\begin{tabular}{|c|c|c|c|c|}
\hline Constructs and Items & $\begin{array}{c}\text { Standardized } \\
\text { Factor loading }\end{array}$ & Cronbach's a & $\begin{array}{l}\text { Composite } \\
\text { Reliability }\end{array}$ & $\begin{array}{c}\text { Average Variance } \\
\text { Extracted(AVE) }\end{array}$ \\
\hline Confidence senvice quality(CSQ) & & .955 & .963 & .790 \\
\hline sincere employee to customer's questions & .929 & & & \\
\hline Employees comporting customers & .910 & & & \\
\hline Employee's performance to customer request & .932 & & & \\
\hline Employees' sincere customer service & .901 & & & \\
\hline Employees' good working & .914 & & & \\
\hline Trust in employees & .908 & & & \\
\hline A neat and clean dress of employee & .706 & & & \\
\hline Fundamental characteristics service quality(FCSQ) & & .909 & .937 & .788 \\
\hline Moderate coffee concentration & .929 & & & \\
\hline Moderate coffee bitter taste & .891 & & & \\
\hline Coffee flavor to customer's preference & .902 & & & \\
\hline Moderate coffee aroma & .825 & & & \\
\hline Physical environment senvice quality(PESQ) & & .859 & .904 & .704 \\
\hline Table's moderate space & .901 & & & \\
\hline Chairs's moderate space & .894 & & & \\
\hline Comfortable chair & .808 & & & \\
\hline Enough chairs & .742 & & & \\
\hline Beverage characteristics service quality(BCSQ) & & .776 & .860 & .675 \\
\hline Various coffee types & .794 & & & \\
\hline The right amount of beverage & .941 & & & \\
\hline The taste of beverage to customers' liking & .714 & & & \\
\hline Representation senvice quality(RSQ) & & .751 & .843 & .652 \\
\hline Having representation food & .876 & & & \\
\hline Having representation beverage & .941 & & & \\
\hline High brand awareness & .550 & & & \\
\hline
\end{tabular}




\begin{tabular}{|c|c|c|c|c|}
\hline Behavior Intention(BI) & & .940 & .957 & .848 \\
\hline I want to visit next time & .937 & & & \\
\hline I want to continue to visit & .927 & & & \\
\hline Positively talk to others & .925 & & & \\
\hline I want to recommend it to others. & .894 & & & \\
\hline Customer satisfaction(CS) & & .912 & .938 & .791 \\
\hline Satisfaction with menu, taste, quality & .931 & & & \\
\hline Overall satisfied & .905 & & & \\
\hline Satisfaction with employee service & .883 & & & \\
\hline Satisfaction with physical environment & .836 & & & \\
\hline Utilitarian value(UV) & & .938 & .955 & .840 \\
\hline appropriate price & .938 & & & \\
\hline reasonable price & .899 & & & \\
\hline Benefits equivalent to the price paid & .927 & & & \\
\hline Excellent quality compared to payment price & .901 & & & \\
\hline Hedonic value(HV) & & .815 & .873 & .637 \\
\hline Pleasure and joy when visiting & .896 & & & \\
\hline Providing a sense of stability when visiting & .826 & & & \\
\hline Having a good feeling to other when visiting & .589 & & & \\
\hline The expense is worth it & .846 & & & \\
\hline
\end{tabular}

Table 3: Fornell-Larcker Criterion

\begin{tabular}{|c|c|c|c|c|c|c|c|c|c|}
\hline & 1 & 2 & 3 & 4 & 5 & 6 & 7 & 8 & 9 \\
\hline 1 CSQ & .887 & & & & & & & & \\
\hline $\begin{array}{ll}2 & \text { FCSQ }\end{array}$ & $.441^{\star *}$ & .839 & & & & & & & \\
\hline $\begin{array}{ll}3 & \text { PESQ }\end{array}$ & $.343^{* \star}$ & $.215^{\star \star}$ & .889 & & & & & & \\
\hline 4 BCSQ & $.515^{\star *}$ & $.303^{\star \star}$ & $.307^{\star \star *}$ & .822 & & & & & \\
\hline RSQ & $.414^{\star *}$ & $.308^{\star *}$ & .106 & $.513^{\star \star}$ & .807 & & & & \\
\hline UV & $.199 * \star$ & $.259 * \star$ & .061 & .120 & .027 & .917 & & & \\
\hline EV & $.390 * *$ & $.340^{\star \star}$ & $.264^{\star \star}$ & $.225^{\star \star}$ & $.282^{\star \star}$ & $.431^{\star \star}$ & .798 & & \\
\hline CS & $.706 * \star$ & $.507^{\star \star}$ & $.313^{\star \star}$ & $.511^{\star \star}$ & $.369 * \star$ & $.467^{\star \star}$ & $.622^{* \star}$ & .889 & \\
\hline BI & $.607^{* *}$ & $.573^{\star \star}$ & $.287^{\star \star}$ & $.530^{* \star}$ & .420 ** & $.365^{\star \star}$ & $.494^{\star \star}$ & $.703^{\star \star}$ & .921 \\
\hline Mean & 5.494 & 5.092 & 4.603 & 5.353 & 4.906 & 4.619 & 4.709 & 5.365 & 5.815 \\
\hline SD & 1.089 & 1.126 & 1.229 & 1.141 & 1.355 & 1.415 & 1.040 & 1.031 & 1.133 \\
\hline
\end{tabular}

** $p<0.01$, - Bold numbers indicate the square root of AVE.

\section{4. 상관관계 분석}

단일차원성이 입증된 각 연구단위 간에 서로의 관계에 대 한 방향성과 어느 정도의 관계를 갖는 지를 알아보기 위해 상관관계 분 석을 실시하였다. 분석 결과, <Table 3>과 같이 나타났으며, 연구모형과 연구가 설에서 제시된 변수들 간의 방향은 일치하는 것으로 나타 났다.

\section{5. 연구가설 검정}

\subsection{1. 연구가설의 검정}

$<\mathrm{H} 1>$ 과 < $\mathrm{H} 2>$ 는 커피전문점 서비스 품질 측정모형인 CoffeeSERV의 5요인(신뢰감, 본원적 특성, 물리적 환경, 커
피 본원적 특성 외 음료의 특성, 대표성)과 지각된 가치를 실용적 가치와 감정적 가치로 구분하여, 서비스 품질과 지각 된 가치의 영향관계를 확인하고자 하는 것이다. 서비스 품질 이 지각된 가치, 고객만족, 행동의도에 미치는 영향에 대한 구조적 관계를 분 석한 결과는 <Table $4>$ 와 같다. 분석 결과, 본원적 특성이 실용적 가치에 미치는 영향에서는 통계적으 로 유의하게 나타나 < $\mathrm{H} 1-1>$ 은 지지되었다 $(\beta=.219, \mathrm{t}=3.091$, $\mathrm{p}=.002)$. 그러나 물리적 환경 $(\beta=-.011, \mathrm{t}=0.132, \mathrm{p}=.895)$, 신 뢰성 $(\beta=.115, \mathrm{t}=1.368, \mathrm{p}=.171)$, 음료 특성 $(\beta=.052, \mathrm{t}=0.571$, $\mathrm{p}=.568)$, 대표성 $(\beta=-.010, \mathrm{t}=0.087, \mathrm{p}=.931)$ 등은 실용적 가 치에 통계적으로 유의한 영향을 미치지 못하였으므로 $<\mathrm{H} 1-2>,<\mathrm{H} 1-3>,<\mathrm{H} 1-4>,<\mathrm{H} 1-5>$ 는 지지되지 않 았다. 
Table 4: Summary of structural model estimation results

\begin{tabular}{|c|c|c|c|c|c|}
\hline & Paths & Estimate & $\mathbf{t}$ & p & Results \\
\hline $\mathrm{H} 1-1$ & Fundamental characteristic SQ $\rightarrow$ Utilitarian value & .219 & 3.091 & $.002^{\star *}$ & Supported \\
\hline $\mathrm{H} 1-2$ & Physical environment SQ $\rightarrow$ Utilitarian value & -.011 & 0.132 & .895 & Non-Supported \\
\hline $\mathrm{H} 1-3$ & Confidence SQ $\rightarrow$ Utilitarian value & .115 & 1.368 & .171 & Non-Supported \\
\hline $\mathrm{H} 1-4$ & Beverage characteristic SQ $\rightarrow$ Utilitarian value & .052 & .571 & .568 & Non-Supported \\
\hline $\mathrm{H} 1-5$ & Representation SQ $\rightarrow$ Utilitarian value & -.010 & .087 & .931 & Non-Supported \\
\hline $\mathrm{H} 2-1$ & Fundamental characteristic SQ $\rightarrow$ Hedonic value & .210 & 3.121 & $.002^{\star \star}$ & Supported \\
\hline $\mathrm{H} 2-2$ & Physical environment SQ $\rightarrow$ Hedonic value & .134 & 2.187 & $.029 * \star$ & Supported \\
\hline $\mathrm{H} 2-3$ & Confidence SQ $\rightarrow$ Hedonic value & .224 & 3.002 & $.003^{* *}$ & Supported \\
\hline $\mathrm{H} 2-4$ & Beverage characteristic SQ $\rightarrow$ Hedonic value & .007 & .102 & .919 & Non-Supported \\
\hline $\mathrm{H} 2-5$ & Representation SQ $\rightarrow$ Hedonic value & .171 & 2.507 & $.012^{*}$ & Supported \\
\hline $\mathrm{H} 3-1$ & Utilitarian value $\rightarrow$ Customer satisfaction & .237 & 5.079 & $.000^{\star \star \star}$ & Supported \\
\hline $\mathrm{H} 3-2$ & Hedonic value $\rightarrow$ Customer satisfaction & .557 & 13.831 & $.000^{\star \star \star}$ & Supported \\
\hline $\mathrm{H} 4-1$ & Utilitarian value $\rightarrow$ Behavioral intention & .018 & .335 & .738 & Non-Supported \\
\hline $\mathrm{H} 4-2$ & Hedonic value $\rightarrow$ Behavioral intention & .110 & 1.792 & .073 & Non-Supported \\
\hline H5 & Customer satisfaction $\rightarrow$ Behavioral intention & .629 & 11.220 & $.000^{\star \star \star}$ & Supported \\
\hline \multicolumn{6}{|c|}{$\mathrm{SMC}\left(\mathrm{R}^{2}\right)$} \\
\hline & Utilitarian value & \multicolumn{4}{|c|}{$.094(9.4 \%)$} \\
\hline & Hedonic value & \multicolumn{4}{|c|}{$.275(27.5 \%)$} \\
\hline & Customer satisfaction & \multicolumn{4}{|c|}{$.490(49.0 \%)$} \\
\hline & Behavioral intention & \multicolumn{4}{|c|}{$.514(51.4 \%)$} \\
\hline
\end{tabular}

* $\mathrm{p}<.05, \quad$ ** $\mathrm{p}<.01, \quad$ *** $\mathrm{p}<.001$

$<\mathrm{H} 2>$ 는 서비스 품질이 감정적 가치에 미치는 영향에 관 한 것이다. 분석결과, 본원적 특성 $(\beta=.210, \mathrm{t}=3.121, \mathrm{p}=.002)$, 물리적 환경 $(\beta=.134, \mathrm{t}=2.187, \quad \mathrm{p}=.029), \quad$ 신뢰감 $(\beta=.224$, $\mathrm{t}=3.002, \mathrm{p}=.003)$, 대표성 $(\beta=.171, \mathrm{t}=2.507, \mathrm{p}=.012)$ 등이 감 정적 가치에 통계적으로 유의한 영향을 미치는 것으로 나타 나 <H2-1>, <H2-2>, <H2-3>, <H2-5>는 모두 지지되었다. 그러나 본원적 특성 외 음료의 특성은 통계적으로 유의한 영향을 미치지 않아 < $\mathrm{H} 2-4>$ 는 기각되었다 $(\beta=.007, \mathrm{t}=0.102$, $\mathrm{p}=.919$ ).

다음으로 < $\mathrm{H} 3>$ 은 지각된 가치가 고객만족에 미치는 영향 에 관한 것이다. 분석 결과, 실용적 가치지각이 고객만족에 미치는 영향 $((\beta=.237, \mathrm{t}=5.079, \mathrm{p}=.000)$ 과 감정적 가치지각이 고객만족에 미치는 영향 $(\beta=.557, \mathrm{t}=13.831, \mathrm{p}=.000)$ 은 모두 통계적으로 유의하였으며, 따라서 <H3-1>, <H3-2>는 모두 지지되었다.

$<\mathrm{H} 4>$ 는 지각된 가치가 행동의도에 미치는 영향에 관한 것이다. 분석 결과, 실용적 가치 $\quad(\beta=.018, \mathrm{t}=0.335$, $\mathrm{p}=.738>05)$, 감정적 가치 $(\beta=.110, \mathrm{t}=1.792, \mathrm{p}=.073>.05)$ 모 두 행동 의도에 유의한 영향을 미치지 못하는 것으로 나타나, $<\mathrm{H} 4-1>,<\mathrm{H} 4-2>$ 모두 지지되지 못하였다.

$<\mathrm{H} 5>$ 는 고객만족이 행동의도에 미치는 영향에 관한 것이 다. 분석결과, 고객만족( $\beta=.629, \mathrm{t}$ 값=11.220, $\mathrm{p}=.000<.001)$ 은 행동의도에 통계적으로 유의한 영향을 미치는 것으로 나 타나 < $\mathrm{H} 5>$ 는 지지되었다.

\subsection{2. 조절효과 분 석}

서비스품질 요인과 지각된 가치, 고객만족, 행동의도의 영 향관계에서 고객의 조절초점동기 성향에 따라 조절적 효과 가 발생할 것이라는 < $\mathrm{H6} 6$ 을 검증하기 위하여 SmartPLS 3.0 을 이용, 구조분석을 실시하였으며, 조절초점동기성향에 따라 구분하여 분 석한 결과는 <Table $5>$ 와 같다.

$<\mathrm{H} 6>$ 의 검증을 위하여, 선행연구에서 조절초점 동기성향 을 분류하기 위해 사용한 Higgins et al.(2001)의 기질적 조 절초점 설문항목(RFQ)의 11 개 문 항을 통하여 개인차를 측 정한 후(Oh, 2015), 향상동기 집단( $\mathrm{N}=107)$ 과 예 방동기 집단 $(\mathrm{N}=120)$ 으로 구분하였다. 각 집단 별로 커피전문점 서비스 품질의 각 요인이 실용적 가치와 감정적 가치에 미치는 영 향과 지각된 가치가 고객만족, 행동의도에 미치는 영향을 알 아보기 위하여 SmartPLS3.0을 이용하여 구 조모형분석이 실 시되었으며, 그 결과는 <Table $5>$ 와 같다.

분석 결과, 본원적 특성 $(\triangle \beta=.226, \mathrm{t}=1.801, \mathrm{p}=.073$; $p<.10)$, 물리적 환경 $(\triangle \beta=.212, t=1.771, p=.078 ; p<.10)$, 신 뢰감 $\triangle \beta=.386, \mathrm{t}=2.958, \mathrm{p}=.003 ; \mathrm{p}<.05)$ 등은 감정적 가 치, 음료 특성 $(\triangle \beta=.322, \mathrm{t}=1.711, \mathrm{p}=.088 ; \mathrm{p}<.10)$ 은 실용 적 가치, 그리고 실용적 가치는 행동의도 $(\triangle \beta=.223, \mathrm{t}=2.083$, $\mathrm{p}=.038 ; \mathrm{p}<.05)$ 의 관계에서만 두 집단 간에 통계적으로 유의 한 차이가 있는 것으로 나타났다. 따라서 < $\mathrm{H6} 6$ 은 부분적으 로 지지되었으며, 조절초점 동기성향은 각 요인들 간의 관계 에 있어서 부분적으로 조절효과가 발생하는 것으로 나타 났 다. 
Table 5: Analysis of moderating effect by regulatory focus group

\begin{tabular}{|c|c|c|c|c|c|c|}
\hline \multirow{2}{*}{ Paths } & \multicolumn{3}{|c|}{ Promotion group } & \multicolumn{3}{|c|}{ Prevention group } \\
\hline & Estimate & $\mathbf{t}$ & p & Estimate & $\mathbf{t}$ & p \\
\hline \multirow{2}{*}{ Fundamental characteristic $\rightarrow$ Utilitarian value } & .263 & 2.483 & .013 & .244 & 2.445 & .015 \\
\hline & \multicolumn{3}{|c|}{ Differences } & .018 & 0.127 & .899 \\
\hline \multirow{2}{*}{ Physical environment $\rightarrow$ Utilitarian value } & -.114 & 0.914 & .361 & .105 & 0.977 & .329 \\
\hline & \multicolumn{3}{|c|}{ Differences } & .219 & 1.343 & .181 \\
\hline \multirow{2}{*}{ Confidence $\rightarrow$ Utilitarian value } & .149 & 1.283 & .200 & .019 & 0.170 & .865 \\
\hline & \multicolumn{3}{|c|}{ Differences } & .130 & 0.811 & .418 \\
\hline \multirow{2}{*}{ Beverage characteristic $\rightarrow$ Utilitarian value } & -.088 & 0.649 & .517 & .234 & 1.780 & .076 \\
\hline & \multicolumn{3}{|c|}{ Differences } & .322 & 1.711 & $.088^{* *}$ \\
\hline \multirow{2}{*}{ Representation $\rightarrow$ Utilitarian value } & .153 & 1.119 & .264 & -.204 & 1.280 & .201 \\
\hline & \multicolumn{3}{|c|}{ Differences } & .357 & 1.688 & $.093^{*}$ \\
\hline \multirow{2}{*}{ Fundamental characteristic $\rightarrow$ Hedonic value } & .106 & 1.122 & .263 & .332 & 3.955 & .000 \\
\hline & \multicolumn{3}{|c|}{ Differences } & .226 & 1.801 & $.073^{\star *}$ \\
\hline \multirow{2}{*}{ Physical environment $\rightarrow$ Hedonic value } & .035 & 0.367 & .714 & .246 & 3.226 & 0.001 \\
\hline & \multicolumn{3}{|c|}{ Differences } & .212 & 1.771 & $.078^{* *}$ \\
\hline \multirow{2}{*}{ Confidence $\rightarrow$ Hedonic value } & .411 & 4.392 & .000 & .024 & 0.266 & 0.790 \\
\hline & \multicolumn{3}{|c|}{ Differences } & .386 & 2.958 & $.003^{*}$ \\
\hline \multirow{2}{*}{ Beverage characteristic $\rightarrow$ Hedonic value } & -.067 & 0.615 & .539 & .139 & 1.421 & .156 \\
\hline & \multicolumn{3}{|c|}{ Differences } & .206 & 1.416 & .158 \\
\hline \multirow{2}{*}{ Representation $\rightarrow$ Hedonic value } & .146 & 1.604 & .109 & .158 & 1.458 & .145 \\
\hline & \multicolumn{3}{|c|}{ Differences } & .012 & 0.086 & .932 \\
\hline \multirow{2}{*}{ Utilitarian value $\rightarrow$ Customer satisfaction } & 211 & 2.977 & .003 & .250 & 3.508 & .000 \\
\hline & \multicolumn{3}{|c|}{ Differences } & .039 & 0.389 & .698 \\
\hline \multirow{2}{*}{ Hedonic value $\rightarrow$ Customer satisfaction } & .582 & 9.349 & .000 & .551 & 10.046 & .000 \\
\hline & \multicolumn{3}{|c|}{ Differences } & .032 & 0.386 & .700 \\
\hline \multirow{2}{*}{ Utilitarian value $\rightarrow$ Behavioral intention } & -.091 & 1.118 & .264 & .133 & 1.855 & .064 \\
\hline & \multicolumn{3}{|c|}{ Differences } & .223 & 2.083 & $.038^{*}$ \\
\hline \multirow{2}{*}{ Hedonic value $\rightarrow$ Behavioral intention } & .088 & 0.912 & .362 & .120 & 1.579 & .115 \\
\hline & & ferenc & & .033 & 0.269 & .788 \\
\hline Customer caticfaction $\rightarrow$ Rehavin & .670 & 7.969 & .000 & .599 & 8.408 & .000 \\
\hline customer sat & & ferenc & & .071 & 0.652 & .515 \\
\hline
\end{tabular}

${ }^{*} p<0.05,{ }^{*} p<0.1$

\section{5. 결론}

본 연구는 커피전문점을 대상으로 서비스품질이 지각된 가치, 고객만족, 행동의도에 미치는 영향관계를 규 명해 보려 는 것이며, 소비자의 조절초점동기성향에 따라 서비스 품질 이 지각된 가치에 미치는 영향, 지각된 가치가 고객만족, 행 동의도와의 관계에서 조절적 차이가 발생하는지를 살펴보고 자 하였다. 또한 국내 연구진에 의해 개발된 커피전문점 서 비스품질 측정도구인 CoffeeSERV를 적용하여 연구하였는 데, 기존의 커피전문점 서비스품질 측정에 사용된 도구들은 외식산업의 특성을 반영하는 데에 한계가 있었다는 판단을 고려할 때 (Yoo \& Kim, 2004), 커피전문점 서비스품질 연구 에서 다소 의미가 있는 접근으로 판단하였다. 따라서 본 연 구의 결과는 CoffeeSERV측정도구를 사용하여 커피전문점 서비스품질의 여 러 특성요인들에 대하여 측정함으로써 커피 전문점의 서비스품질을 관리하고 개선할 수 있는 기초자료 로 사용 될 수 있을 것이다.
한편 소비자 개인차 변수의 하나인 조절초점이론을 적용 하여 소비자의 동기성향에 따라 서비스품질이 소비자의 가 치지각, 고객만족, 행동의도의 관계에 조절적 영향을 미치는 지를 살펴보고자 하였으며, 소비자의 동기성향에 따 른 서비 스품질에 대한 각 변수들 간의 영향관계의 차이는 고객지향 적인 고객 응대전략 수립에 유의미한 근거자료를 제공할 수 있을 것으로 판단하였다.

본 연구는 커피전문점 서비스품질 측정도구인 CoffeeSERV 의 5 개 차원, 실용적 가치와 감정적 가치, 고객만족, 행동의 도 등 구성변수들의 영향관계를 연구모형으로 구성하여 가 설설정 및 실증하였으며, 주요 연구결과는 다음과 같다.

가설 검증 결과, 첫째, 커피전문점 서비스품질 측정도구 CoffeeSERV의 5차원(신뢰감, 본원적 특성, 물리적 환경, 본 원적 특성 외 음료의 특성, 대표성)중 본원적 특성 요인만이 실용적 가치에 유의한 영향을 미 쳤으나, 감정적 가치에는 서 비스 품질의 5 개 요인 중 음료특성을 제외한 4 개 요인이 모 두 유의한 영향을 미치는 것으로 나타 났다.

둘째, coffeeSERV측정모형의 서비스 품질의 지각된 가치, 고객만족과 행동의도의 영향 관계에서 부분적으로 설정된 
가설을 지지하고 있음을 확인하였다.

셋째, 커피전문점 서비스품질이 지각된 가치에 미치는 영 향관계에서 조절초점동기성향에 따라 차이가 발생할 것이라 는 가 설을 검증하기 위한 구 조분석 결과, 실용적 가치의 경 우, 음료 특성 요인에서 두 조절초점동기 집단 간에 유의한 조절효과가 발생한다는 것을 확인하였다. 그러나 나 머지 4 개의 하위요인에서는 유의미한 조절효과가 발생하지 않 았다. 한편 감정적 가치에서는 서비스 품질의 5 개 차원 중 본원적 특성, 물리적 특성, 신뢰감 요인이 두 집단 간에 통계적으로 유의미한 조절효과가 발생하는 것을 확인하였으며, 음료 특 성과 대표성에서는 유의하지 않았다.

분석 결과를 근거로 본 연구의 시사점은 다음과 같다. 첫 째, 커피전문점 서비스품질 측정도구 CoffeeSERV를 적용하 여 대 학생을 대상으로 서비스품질과 지각된 가치, 고객만족, 행동의도의 영향 관계를 살펴보았으며, 서비스품질 요인 중 본원적 특성은 실용적 가치에 유의한 영향을 미치고 있었지 만, 물리적 환경, 신뢰성, 본원적 특성 외 음료의 특성, 대표 성 등에서는 실용적 가치에 영향을 미치지 않는 것으로 나 타났다. 본원적 특성은 제품 즉, 커피 본연의 특성에 관한 것이다. 커피의 맛과 향, 농도 등에 대하여 고객들은 제품 본연의 실용적 가치에 반 응하고 있음을 확인할 수 있다. 고 객의 실용적 가치 지각과 관련하여 Babin, Lee, Kim, and Griffin(2005)은 기 능적(functional) 품질은 과업과 관련하여 실용적 서비스 가치와 관련이 있으며, 실용적 가치는 소비자 만족과 구전에 직접적으로 영향을 주고, 또한 지각된 실용적 가치의 하락은 이러한 중요한 결과를 감소시키게 될 것이라 고 하였는 데, 서비스 품질의 본연적 특성은 기 능적 가치 요 소와 관련된 것으로서 Babin et al.(2005)의 주장과 상당 부 분 일치하는 것이라 할 수 있다.

한편 종업원, 점포의 환경, 제공되는 서비스의 절차 등에 대하여는 영향 관계가 유의하지 않게 나타난 것은 고객의 트렌드의 변화를 반영한 것이거나 특정 소비자집단에서 나 타나는 현상일 수 있다. 즉 고객이 대 학생으로 한정되어 있 고, 점포 등의 환경에 대한 기대 수준이 비 일반적인 상태에 있을 수도 있기 때문에 이에 대해서는 보다 확장된 소비 집 단에서 검증이 필요한 부분이라고 판단된다. 그러나 감정적 가치에 대한 서비스 품질의 영향 관계에서는 본원적 특성 외 음료의 특성을 제외하고는 대부분의 서비스품질 요인들 이 유의한 영향을 미치는 것으로 나타났으므로 소비자들은 점포에서 제공되는 제품과 서비스에 대하여 지각하는 감정 적 가치의 비중이 보다 더 높은 것으로 추 론할 수 있다. 감 정적 가치는 제품이나 서비스로부터의 정서적 상태나 느낌 이 만들어 내는 유용성이라고 할 수 있다. 즉, 소비자가 제 품이나 서비스에 대해 긍정적인 느낌을 가질 때 감정적 가 치에 대한 만족감은 높아진다(Sweeney \& Soutar, 2001). 따 라서 제품과 서비스 경험으로부터 지각된 감정적 가치는 고 객으로 하여금 편익을 지각하게 하며, 이때 고객들이 점포내 의 경험을 바탕으로 편익을 얻게 될 경우, 점포에 대한 태도 가 호의적으로 변화하여 재방문이나 우호적인 구전활동으로 이어지는 서비스 이 익 사슬관계의 중요요인으로 형성하도록 작용할 수 있을 것이다(Park, Lee, \& Lee, 2015).

둘째, 커피전문점 서비스품질 측정모형인 CoffeeSERV를
적용한 선행연구가 드문 가운 데, CoffeeSERV를 적용한 연 구로서 확장적 의미를 제시를 할 수 있다고 판단하였으나, 실용적 가치지각의 경우, 본원적 특성을 제외하고는 물리적 환경, 신뢰성, 커피 본원적 특성 외 음료의 특성, 대표성 등 대부분의 서비스품질 요인에서 실용적 가치지각이 이 루어지 지 않은 것에 대하여는 연구자들이 CoffeeSERV 측정모형 개발과정에서 충분한 검증을 통해 커피전문점의 서비스품질 을 측정하는 신뢰성과 타당성을 갖춘 척도(Park \& Yoon, 2006)라고 하였어도 척도의 적 절성 여부를 검토하고 보 완하 는 문제를 제기할 수 있을 것으로 판단되었다.

셋째, 본 연구는 서비스품질 요인에 대한 가치지각을 통 해 고객들의 만족과 행동의도를 확인하고자 하는 것이었다. 실증 분 석을 통하여 특히 실용적 가치에 영향을 주는 서비 스품질 요인 중, 본원적 특성을 제외한 4 가지 요인은 서로 영향 관계가 형성되지 않는 것으로 나타났다. 한편 PZB (1985)는 자 신들의 연구에서 물리적 환경이 서비스품질을 높게 평가하도록 유도할 수 있다고 하였다. 그러나 본 연구 에서는 커피전문점의 서비스품질에 대한 가치 지각에 대 학 생들은 물리적 환경의 영향은 유의하지 않은 것으로 나타 났 다. 이것은 조사응답자들이 경험하는 커피전문점의 인 테리 어를 포함, 깨끗하고 쾌적한 환경, 내부의 테이블 배치 등 물리적 환경요인들에 대한 가치 지각 수준이 매우 높아진 탓에 현재의 커피전문점에 대한 인식 수준의 변화에 따 른 영향력에서 차이가 발생한 탓일 수도 있을 것이다. 따라서 커피전문점은 이 러한 서비스품질 요인에 대한 고객의 지각 수준에 따라 대 응노력을 기 울일 필요가 있을 것으로 판단된 다. 신뢰성, 물리적 환경, 본원적 특성 외 음료의 특성, 대표 성 등 커피전문점에 특화된 측정요인들에 대한 영향관계가 유의하지 않은 것은 조사과정의 문제점만이 아닌, 근원적인 문제점이 발생되고 있는 신호일 수도 있으며, 이에 대한 추 가적인 검토가 필요하다고 여 겨진다.

넷째, 조절초점동기에 따라 향상동기집단과 예 방동기집단 이 지각하는 서비스품질 수준은 가치 지각요소 중, 실용적 가치와 감정적 가치에 각각 다 른 영향을 미칠 것으로 예상 하면서 소비자들의 개인성향의 차이를 확인하고자 하였다. 고객들은 향상동기와 예 방동기 등 본인이 지 니고 있는 동기 적 특성에 따라 마케팅 대상의 유형과 극성에 대한 적 합성 여부를 느끼게 되며, 이는 본인의 동기성향에 따라 선 택적으 로 지각하거나 해 석하는 것이 더 수 월해지므로 자 신의 성향 에 어 울리는 대상 정보를 바탕으로 의사 결정에 활용할 것으 로 예상하였다(Safer \& Higgins, 2001). 검증 결과, 일부의 요인에서 두 집단 간의 통계적으로 유의미한 차이를 확인할 수 있었으며, 향후 고객의 특성이나 기대욕구에 대한 차이를 고려하여 응대전략을 수립하고 이에 따라 고객서비스 강화 에 기여할 수 있을 것으로 예상하였다.

본 연구가 가진 한계점은 다음과 같다. 첫째, 조사대상의 선정의 문제가 있을 수 있다. 대학생이라고 하는 특정 대상 을 중심으로 한 연구이므로 연구 결과를 일반화하기 어 렵다. 그러나 핵심 고객층이라 할 수 있는 대 학생 등 젊은 층을 대상으로 하는 마케팅에서는 이 연구가 연구의 가이드라인 을 제시할 수 있을 것이다.

둘째, 조절초점동기이론을 도 입하여 고객의 개인 성향에 
따른 조절적 영향을 살펴보고자 하였으며, 일부의 서비스 품 질 요인에서 통계적으로 유의미한 결과를 확인할 수는 있었 다. 기질적 조절초점동기를 파악하여 집단을 구분하였으며, 일부의 요인에서 두 집단 간 기대한 결과가 나타난 것은 본 연구의 의미있는 접근으로 평가할 수 있을 것으로 판단된다. 다만 CoffeeSERV 측정변수를 활용한 후속 연구가 부족한 현실에서 이 모형의 활용가치에 대한 의문이나 영향력 수준, 그리고 실증 연구과정에서 데이터 확보에 영향을 미치는 연 구방법 상의 문제도 발생할 수 있을 것이기에 앞으로 이를 보완할 적 절한 연구방법을 고려할 필요가 있을 것이다. 조절 초점동기집단 간의 성향차이를 확인하고자 하는 연구는 소 비자 욕구의 다양성에 대 응해야 하는 마케팅환경에서 소비 자의 개인차를 고려하는 것은 자연스런 관심주제가 될 수 있을 것으로 판단된다.

\section{References}

Babin B. J., Darden, W. R., \& Griffin, M.(1994), Work and/or fun: Measuring hedonic and utilitarian shopping value, Journal of Consumer Research, 20(4), 644-656.

Babin, B. J., Lee, Y. K., Kim, E. J., \& Griffin, M. (2005). Modeling consumer satisfaction and word-of-mouth: restaurant patronage in Korea. Journal of Services Marketing, 193), 133-139.

Batra, R., \& Ahtola, O. T. (1991). Measuring the hedonic and utilitarian sources of consumer attitudes. Marketing Letters, 2(2), 159-170.

Boulding, W., Kalra, A.., \& Staelin, R. (1993). A dynamic process model of service quality: From expectations to behavioral intentions. Journal of Marketing Research, 30(1), 7-27.

Brady, M. K., \& Cronin J. J. (2001). Some new thoughts on conceptualizing perceived service quality: A hierarchical approach, Journal of Marketing, 65(3), 34-49.

Butz, H. E. J., \& Goodstein, L. D.(1996). Measuring customer value: Gaining the strategic advantage, Organizational Dynamics, 24(Winter), 63-77

Chen, C. F. (2008). Investigating structural relationships between service quality, perceived value, satisfaction and behavioral intentions for air passenger: Evidence from Taiwan. Transportation Research Part A, 42(4), 709-717.

Chen, P. T., \& Hu, H. H.(2010). How determinant attributes of service quality influence customer-perceived value: An empirical investigation of the Australian coffee outlet industry. International Journal of Contemporary Hospitality Management, 22(4), 535-551.

Cheon, D. H., Hong, K. W., \& Kim, H. C. (2013). Adapting the hierarchical service quality model (HSQM) proposed by Brady and Cronin to analyze the relationship among service quality, perceived value, satisfaction, and behavioral intention. Journal of Korea Service Management Society, 14(3), 243-261.
Cho, S. H., \& Kang, H. S. (2011). The effects of coffee shop image and perceived value on customer satisfaction, repurchasing intentions and customer switching intentions. Journal Korea Society of Visual Design Forum, 30(0), 43-56.

Cho, Y. H., Chang, D. S., \& Chae, G. J. (2012). A study on casual model of service quality, service value, customer satisfaction and loyalty of airlines in korea. Journal of Korea Service Management Society, 13(2), 1-23.

Choi, H. M., \& Lee, H. R. (2011). The effect of coffee shop customers' experiential value on brand attitude and brand loyalty: A focus on the moderating effect of brand nationality. Journal of Tourism Sciences, 35(3), 243-266.

Choi, M. S., Koo, D. W., \& Lee, S. M. (2017). The effect of customers' perceived value on revisit intentions and word of mouth in coffee chains: The moderating effect of gender. Journal of Franchise Management, 8(1), 43-53.

Choi, S. I., Ahn, J. S., \& Lee, S. B. (2015). The effects of the selective attributes of coffee shop on perceived value and customer loyalty. Journal of Tourism and Leisure Research, 277), 319-340.

Choi, T. H., \& Jun, J. H. (2007). The effect of the brand image on customer satisfaction \& revisit intention in foodservice industry. Journal of Foodservice Management, 104), 151-172.

Cole, S. T. \& Scott, D. (2004). Examining the mediating role of experience quality in a model of tourist experience. Journal of Travel \& Tourism Marketing, 16(1), 79-90.

Conover, W. J., Wehmane, O., \& Ramsey, F. L. (1980). A note on the small sample power functions for nonparametric tests of location in the double exponential family. Journal of the American Statistical Association, 73(361), 188-190.

Cronin, J. J., \& Taylor, S. A. (1992). Measuring service quality: A reexamination and extension. Journal of Marketing, 56(3), 55-68.

Dubroski, D. (2001). The role of customer satisfaction in achieving business excellence. Total Quality Management, 12(7), 920-925.

Garvin, D. (1987). Competing on the eight dimensions of quality. Harv. Bus. Rev. November-December, 101-109.

Grönroos, C. (1984). A service quality model and its marketing implications. European Journal of Marketing, 18(4), 36-44.

Ha, Y. W., \& Kim, Y. D.(2011). The influence of regulatory focus on financial consumers' investment behavior: The moderating role of regulatory focus in the disposition effect and post-disposition risky alternative choice behavior. Korean management review, 403), 605-631.

Ha, Y. W., \& Kim, Y. D. (2014). Differential judgments for self and others: The moderating effects of regulatory focus and the gain/loss domain. Korean management review, 43(2), 303-328.

Hair Jr, J. F., Hult, G. T. M., Ringle, C., \& Sarstedt, M. (2016). A primer on partial least squares structural 
equation modeling(PLS-SEM). sage publications.

Han, J. S., \& Hyun, K. S. (2009). The effect of family restaurants' customer value on satisfaction and behavior intention: Focused on university student in seoul. Korean Journal of Hospitality \& Tourism, 18(1), 135-150.

Hanzaee, K. H. \& Rezaeyeh, S. P. (2013). Investigation of the effects of hedonic value and utilitarian value on customer satisfaction and behavioural intentions. African Journal of Business Management, 711), 818-825.

Higgins, E. (1997). Beyond pleasure and pain. American Psychologist, 52(12), 1280-1300.

Higgins, E. (1998). Promotion and prevention: Regulatory focus as a motivational principle. Advances in experimental social psychology, 30, 1-46.

Higgins, E., Shah, J., \& Friedman, R. (1997). Emotional responses to goal attainment: Intensity of regulatory focus as moderator. Journal of Personality and Social Psychology, 72(3), 515 535.

Hirschman, E. C. (1986). Humanistic inquiry in marketing research: Philosophy, method, and criteria. Journal of Marketing Research, 23(3), 237 -249.

Hirschman, E. C. \& Holbrook, M. B. (1982). Hedonic consumption: Emerging concepts, methods and propositions. Journal of Marketing, 46(3), 92-101.

Holbrook, M. B. (1994). The nature of customer value: An axiology of services in the consumption experience, in service Quality: New directions theory and practice. Roland T. Rust \& Richard L. Oliver,(Eds.), Thousand Oaks, CA: Sage Publications: 21-71.

Holbrook, M. B. \& Hirschman, E. C. (1982). The experiential aspects of consumption: consumer fantasies, feelings, and fun. Journal of Consumer Research, 9(2), 132-140

Holbrook (1986). Aims, concepts, and methods for the representation of individual differences in esthetic responses to design features. Journal of Consumer Research, 13(3), 337-347.

Howard, J. A., \& Sheth, J. N. (1969). The theory of buyer behavior. In Harold, H. K., \& Thomas, S. R. (eds), Perspectives in consumer behavior (pp467-87), Glenview III: Scott, Horesman \& Co.

Hunt, H. K. (1977). CS/D overview and future research direction in conceptualization and measurement of consumer satisfaction and dissatisfaction. In Hunt, $\mathrm{H} . \mathrm{K}$. ed. Cambridge, M.A.: Marketing Science Institute.

Hyun, K. S., \& Han, J. S. (2009). The influence of hotel service's physical environment on customer value and behavioral intention. Journal of Tourism Sciences, 33(2), 327-347.

Jones M. A., Reynolds, K. E., \& Arnold, M. J. (2006). Hedonic and utilitarian shopping value: Investigating differential effects on retail outcomes. Journal of business research, 5999), 974-981.

Kandampully, J., \& Duddy, R. (1999). Competitive advantage through anticipation, innovation and relationships, Management Decision, 371), 51-56.
Kandampully, J., \& Liam, B. (2001). Service guarantees: A strategic mechanism to minimise customers' perceived risk in service organizations. Managing Service Quality, 1(2), 112-120.

Kim, C. G. (2011). The execution of customer value creation management for gaining of competitive advantage. Journal of Korean Regional Development, 10(2), 1-25.

Kim, E. J., Kim, S. H., \& Lee, Y. K. (2019). The effects of brand hearsay on brand trust and brand attitudes. Journal of Hospitality Marketing \& Management, 1-20.

Kim, E. J., Lee, Y. K., \& Hwang, J. K. (2015). The effect of self-congruity on functional congruity, perceived value, and attitude in franchise coffee shops. Journal of Franchise Management, 6(1), 69-90.

Kim, G. J., \& Byun, G. I. (2010). The comparison of homemade and foreign coffee shop brands in potential effects of their service quality on satisfaction and behavioral intentions of customers. Korean Journal of Hospitality \& Tourism, 194), 187-206.

Kim, J. G., \& Song, K. S. (2010). The effect of perceived quality and value on customer commitment and loyalty in chain-typed coffee houses. Journal of Foodservice Management Society of Korea, 13(5), 67-93.

Kim, K. S., \& Won, H. Y. (2005). A study on the effects of the perception of guests about eating out value on customer satisfaction of dining out. Journal of Foodservice Management Society of Korea, 8(1), 67-85.

Kim, Y. G. (2012). Effects of dimensions of price on the consumers' eating out value and satisfaction: Focused on family restaurants. Journal of Foodservice Management Society of Korea, 15(5), 55-71.

Ko, H. J., Park, J. W., Kim, K. P., \& Park, H. Y. (2012). The effects of consumers' regulatory focus, product and message types in information processing. Journal of Outdoor Advertising Research, 9(1), 5-32.

Kotler, P., \& Armstrong, G. (2008), Principle of marketing (12thed.). Upper Saddle River, NJ: Prentice Hall.

Kwun, D. J. W. (2011). Effects of campus food service attributes on perceived value, satisfaction, and consumer attitude: A gender-difference approach. International Journal of Hospitality Management, 30(2), 252-261.

Lee, A. J., Park, D. H., \& Park, J. W. (2003). Effect of the service quality of foodservice industry on customer satisfaction, revising intention and oral transmitting intention. Korean Journal of Hospitality \& Tourism, 12(1), 191-213.

Lee, J. H. (2007). The impact of restaurant service quality on perceived value, satisfaction, and behavior intention. Journal of Tourism Sciences, 31(5), 97-118.

Lee, J. H., \& Kang, C. H. (2017). A study on the correlation among service quality, perceived value, and customer satisfaction of specialty coffee shops. Journal of Tourism Management Research, 21(6), 95-122.

Lee, H. S., Kim, Y., \& Jeong, J. H. (1999). Utilitarian/ hedonic shopping value and shopping satisfaction: 
Development and testing of a structural model. Korean management review, 28(2), 505-538.

Lee, H. J., \& Suh, J. Y. (2012). A comparison of local and global coffee shop brands and the effect of their physical environment on customer satisfaction and revisit intention: Based on university students in Seoul. Korean Journal of Hospitality \& Tourism, 21(2), 131-147.

Lee, H. Y., Moon, J. Y., \& Choi, S. Y. (2012). A study on multi-dimensional quality and multi-dimensional customer value of restaurant service: Comparison of family restaurant with fast-food restaurant. International Journal of Tourism Management and Sciences, 273), 311-335.

Llosa, S., Chandon, J. L., \& Orsingher, C. (1998). An empirical study of SERVQUAL's dimensionality. The Service Industries Journal, 18(2), 16-44.

Mitra, D., \& Golder, P. N. (2006). How does objective quality affect perceived quality? Short-term effects, long-term effects, and asymmetries. Marketing Science, 25(3), 230-247.

Moon, S. J., \& Bae, H. J. (2013). The effect of relational benefits on customer perception of value, satisfaction, and loyalty in the specialty coffee shop business. Journal of the Korean Society of Food Science and Nutrition 42(1), 120-128.

Oh, H. Y. (2015). A study of factors affecting the adoption intention of mobile easy payment service. Journal of Financial Services Consumers, 5(1), 33-64.

Oliver, R. L. (1981). What is customer satisfaction? The Wharton Magazine, 5, 36-41.

Oliver, R. L. (1993). Conceptual model of service quality and service satisfaction: Compatible goals, different concepts, Advanced in Services Marketing and Management. 2, 65-85.

Parasuraman, A., \& Grewal, D. (2000). The Impact of technology on the quality-value-loyalty chain: A research agenda. Journal of Academy of Marketing Science, 28(1), 168-174.

Parasuraman, A., Zeithaml, V. A., \& Berry, L. L. (1985). A conceptual model of service quality and its implication for future research. Journal of Marketing, 494), 41-50.

Parasuraman, A., Zeithaml, V. A., \& Berry, L. L. (1988). SERVQUAL: A multiple item scale for measuring consumer perception of service quality. Journal of Retailing, 64(1). 12-40.

Park, H. J., Lee, Y. K., \& Lee, J. W. (2015). The impact of environment characteristics on perceived value and visit intention in franchise coffee shops. Journal of Franchise Management, 6(2), 105-122.

Park, J. C., Oh, H. Y., \& Hong, S. J. (2011). The investigating of psychological mechanism in the "service quality-customer satisfaction" relation. Journal of consumer studies, 22(2), 179-202.

Park, K. H., \& Yoon, J. H. (2006). CoffeeSERV: Multiple-item scale for measuring service quality of specialty coffee shop. Journal of Foodservice Management
Society of Korea, 9(3), 7-26.

Rust, R. T., \& Oliver, R. L. (1994). Service quality: insights and managerial implications from the frontier. Rust, R. T. \& Oliver, R. L. (eds). Service quality: New directions in theory and practices(pp. 1-19), CA: Sage Publications.

Ryu, G. S., Park, J. C., \& Kwon, S. W. (2006). The effect of regulatory focus on the choice of a compromise option. Korean Journal of Marketing, 21(4), 49-65.

Safer, D. A., \& Higgins, E. T. (2001). How do personal concerns influence preferences? The case of promotion and prevention concerns. working paper, Department of Psychology, Columbia University.

Schechter, L. (1984). A normative conception of value. progressive grocer executive report, 12-24.

Sivadeas, E., \& Prewitt, J. B. (2000). An examination of the relationship between service quality, customer satisfaction, and store loyalty. International Journal of Retail and Distribution Management, 28(2), 73-82.

Suh, J. Y., \& Lee, H. J. (2011). A study on the coffee shop's service quality impacts on the customer's satisfaction, trust and recommend convention: Comparison of homemade and foreign coffee shop brands. The Academy of Customer Satisfaction Management, 13(3), 151-172.

Sweeny, J. C., \& Soutar, G. N. (2001). Consumer perceived value: The development of a multiple item scale, Journal of Retailing, 772), 203-220.

There is no place to close even in this recession; 'Gangnam undefeated Starbucks'. (2018, December 03). JoongAng Daily..

Varki, S., \& Colgate, M. (2001). The role of price perceptions in an integrated model of behavioral intentions. Journal of Service Research, 3(3), 232-240.

Woodruf, R. B. (1997). Consumer value: The next source for competitive advantage. Journal of the academy of Marketing Science, 25(2), 139-153.

Woods, W. A. (1960). Psychological Dimensions of Consumer Decision. Journal of Marketing, 24(3), 15-19.

Yi, Y. J. (2004). Service marketing. Seoul: Hakhyunsa.

Yi, Y. J., \& La, S. A. (2011). Investigating the superiority across service quality models: Focusing on SERVQUAL, Grönroos', and three-dimensional quality models. Service Marketing Journal, 4(2), 91-126.

Yi, Y. J., \& Lee, J. Y. (1997). A comprehensive review of service quality: Focusing on concepts and measurements. SNU, Journal of Management Case Research, 31(3/4), 249-283.

Yi, Y. J., \& Lee, J. Y. (2001). A reexamination of the measurement and consequences of service quality: Development and application of the KS-SQI model. Korean Journal of Marketing, 161), 1-26.

Yoo, J. L., \& Kim, Y. G. (2004). A critical review of the service quality study in restaurants. Korean Journal of Hospitality \& Tourism, 13(2), 149-163.

Zeithaml, V. A. (1988). Consumer perceptions of price, 
quality, and value: A means-end model and synthesis of evidence. Journal of Marketing. 52(3). 2-22.

Zeithaml, V. A., Berry, L. L., \& Parasuraman, A. (1996). The behavioral consequences of service quality. Journal of Marketing, 60(2), 31-46. 